\title{
REI LEAR: TEXTO, PERFORMANCE E ADAPTAÇÃO
}

Paulo da Silva Gregório*

iD https://orcid.org/0000-0001-7454-333X

Como citar este artigo: GREGÓRIO, P. da S. Rei Lear: texto, performance e adaptação. Todas as Letras - Revista de Lingua e Literatura, São Paulo, v. 23, n. 1, p. 1-17, jan./abr. 2021. DOI 10.5935/1980-6914/eLETLT2113386

Submissão: maio de 2020. Aceite: julho de 2020.

Resumo: Este artigo examina como Rei Lear ganha sentido no palco e na tela por meio de práticas adaptativas que transcendem o texto shakespeariano. As noções de heteroglossia e dialogismo propostas por Bakhtin (1981) serão invocadas como caminhos para se entender a interação dialógica de vários textos, linguagens e discursos pela qual Rei Lear é reinventada em diferentes contextos e mídias. Olhar para a peça a partir de um prisma dialógico amplia o escopo de uma visão textocêntrica de Shakespeare, a qual posiciona o texto como um artefato estável e a principal fonte de significado em produções shakespearianas para o palco e para a tela. Veremos como Lear foi ressignificada, de modo distinto, por meio de associações com o teatro moderno em uma montagem teatral e uma adaptação fillmica da peça.

Palavras-chave: Shakespeare. Rei Lear. Performance. Adaptação. Bakhtin. 


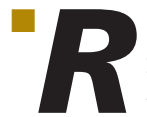

ei Lear é considerada uma das grandes tragédias do cânone shakespeariano. Justapondo figuras da realeza com mendigos, num cenário que progressivamente se desloca de palácios para uma área descampada, a peça retrata a destruição de um mundo pagão onde crueldade, violência, gentileza, lealdade e afeto coexistem lado a lado. Depois que bane Cordélia e divide o reino entre Goneril e Regan, utilizando como critério pueril a veemência com que cada uma professa o afeto que sente por ele, Lear sai de uma situação de poder e passa a percorrer uma trajetória árdua que culmina na sua completa deterioração. O universo de Rei Lear se assemelha a um "imenso palco de loucos" (SHAKESPEARE, 1997, p. 75), onde os cegos são os que verdadeiramente veem, os lunáticos são os verdadeiros filósofos e de onde a única saída é a morte, conforme assinala Guntner (2007, p. 133). O vasto escopo de Rei Lear já levou críticos a apontá-la como inapropriada para o palco ${ }^{1}$, reputação que foi alterada drasticamente no século XX, quando apareceram montagens teatrais de sucesso na Inglaterra. Foakes (2001, p. 1-2) aponta que Lear passou a ser totalmente aceita como uma grande obra teatral a partir do período pós-Segunda Guerra. As diversas montagens de Rei Lear para o palco têm desempenhado um papel fundamental em não apenas ressaltar a intrínseca teatralidade da peça, mas também em explorar seu potencial para ser reinventada de modo significativo para espectadores contemporâneos. Do mesmo modo, adaptações cinematográficas e televisivas são veículos importantes por meio dos quais a peça tem sido continuamente ressignificada e compreendida diferentemente por leitores e espectadores em épocas e contextos distintos. Neste artigo, discutirei como Rei Lear adquire sentido a partir de práticas multidiscursivas que não apenas transcendem o texto, mas também desestabilizam abordagens tradicionais de Shakespeare como texto, as quais enfatizam velhas noções de autoria, imanência, originalidade, universalidade e autenticidade/fidelidade textual. Apesar de já terem sido amplamente problematizados, tais conceitos ainda são entendidos por alguns como chaves para se interpretar Shakespeare. Em contraponto a esse viés, as noções bakhtinianas de heteroglossia e dialogismo chamam a atenção, de modo mais abrangente, para a justaposição dialógica de elementos textuais e não textuais nos processos de construção de sentido. Dentro dessa epistemologia, aquelas concepções mais tradicionais dão lugar a uma visão de arte que é multidiscursiva, intertextual, colaborativa e situada em contextos socioculturais específicos. Compreendido a partir desse ângulo, Shakespeare - o centro do cânone, o Bardo - é repensado como "Shakespeare" (assim mesmo, entre aspas) - uma construção cultural constantemente moldada tanto textual quanto performaticamente, muitas vezes por meio de influências institucionais, comerciais e ideológicas ${ }^{2}$. Essas questões serão discutidas em relação a uma produção teatral e uma adaptação fílmica de Rei Lear dirigidas por Peter Brook. Observarei como a peça foi ressignificada, principalmente, a partir da apropriação de formas dramáticas marcadamente beckettianas. Veremos que o uso de Beckett para recriar Lear no palco e na tela refletiu práticas institucionais da Royal Shakespeare Company (RSC), especificidades

\footnotetext{
A. C. Bradley (1966, p. 202), por exemplo, declarou que Lear era muito grande para o palco. Do mesmo modo, Charles Lamb afirmou que a peça não pode ser encenada (apud BARNET, 1998, p. 249).

2 Esse modo de abordar Shakespeare para além do texto e da figura canônica não é novidade. Já no início do século XXI, Graham Holderness (2001, p. 4) destacava que não podemos simplesmente aplaudir e reverenciar Shakespeare, o homem, o dramaturgo, o Bardo nacional, de maneira inocente.
} 
da linguagem cinematográfica e o contexto sociocultural britânico dos anos 1960, em meio ao qual o teatro de Beckett representava o que havia de mais moderno e contemporâneo.

\section{"The Play is THE THING": TeXto, PALCO E TELA}

He was not of an age, but for all time! (JOHNSON, 2005, p. 343).

Antes de me voltar para as duas produções de Rei Lear, será válido revisitar noções de texto, performance e adaptação que serão pertinentes para compreendermos como a construção de sentido da peça engloba práticas multidiscursivas que vão além do texto shakespeariano. A citação acima, retirada de um famoso poema em que Ben Johnson faz um tributo a Shakespeare e exalta a grandeza dele diante de outros dramaturgos contemporâneos, até hoje ecoa no modo como se compreende Shakespeare. No verso citado, Johnson proclama que o filho de Stratford-upon-Avon não foi apenas de uma época, mas de todos os tempos. Ou seja: embora a obra shakespeariana tenha sido produzida no que se conhece como era elisabetana, ela transcende aquele contexto histórico sem perder seu significado e relevância. O modo como as peças e a reputação de Shakespeare têm se projetado ao longo do tempo, e nas mais diversas localidades ao redor do mundo, parece confirmar o que Johnson profetizou no século XVII. O repertório teatral de companhias como a Royal Shakespeare Company (especializada em montar peças shakespearianas), as traduções, adaptações (literárias, teatrais, filmicas), memes, pinturas, exposições e arquivos são alguns exemplos da presença contínua de Shakespeare em várias esferas socioculturais. Personagens como Hamlet e Romeu e Julieta - bem como a iconografia associada a eles - já fazem parte de um imaginário coletivo, sendo muitas vezes invocadas como avatares de temas como vingança e amor impossivel, mesmo por quem nunca leu ou viu as peças. O contexto educacional também tem contribuído para uma contínua disseminação de Shakespeare: além de ser componente obrigatório do currículo escolar de países como o Reino Unido, há toda uma indústria acadêmica dedicada aos estudos shakespearianos. Foi, inclusive, por meio de uma crítica shakespeariana mais tradicional, representada por nomes como Harold Bloom, que Shakespeare foi posicionado no centro do cânone ocidental e adquiriu um status mítico de criador da natureza humana ${ }^{3}$. Nessa perspectiva, o texto de Shakespeare ganha um espaço igualmente central, sendo muitas vezes apontado como o principal veículo para a difusão do dramaturgo e a manutenção de sua relevância em nivel global.

Pensar Shakespeare como uma figura literária, que produziu sua obra para publicação, preocupado com autoria e originalidade, é desconsiderar, entretanto, o homem de teatro que ele foi e o processo colaborativo que embasou a produção e a recepção inicial de suas peças. Stanley Wells $(2001$, p. 28) aponta que a influência de elementos como ensaio e performance na construção das peças se revela no modo como Shakespeare elaborou diálogos em consonância com

\footnotetext{
Em The western canon, Bloom (1994, p. 46, tradução minha) destaca que "Shakespeare e Dante são o centro do cânone pois eles superam todos os outros escritores ocidentais em acuidade cognitiva, vigor linguístico e poder de invenção". Em Shakespeare: the invention of the human, ele vai mais além, apontando que "a personalidade... é uma invenção shakespeariana" (BLOOM, 1998, p. 4, tradução minha).
} 
estilos de atuação e formatos dos teatros da época. Além disso, as peças eram submetidas a revisões constantes durante o período em que eram encenadas, e contavam com a colaboração de outros dramaturgos contemporâneos. Conforme assinala John Jowett (2008, p. 132), há evidências da contribuição de outros escritores em Henrique VI, Henrique VIII, Tito Andrônico, Medida por medida, Macbeth e Timão de Atenas. Desse modo, entender a obra shakespeariana como produto de um contexto teatral em que outros elementos, além da figura do dramaturgo, participavam ativamente da construção de sentido contraria noções de que uma obra de arte é um produto original fabricado exclusivamente a partir da consciência do autor, cujas intenções são impressas no texto e atuam como fonte principal de significado. Não se pode esquecer que as peças também resultaram de um complexo trabalho de apropriação intertextual. Jay Halio (2005, p. 2) nos informa que embora The chronicle history of King Leir, de Holinshed, tenha sido a principal fonte textual para Rei Lear, outras obras como Historia Regum Brittaniae, de Geoffrey of Monmouth, também foram apropriadas por Shakespeare na criação da peça. Tendo em vista esse caráter intertextual do teatro shakespeariano, torna-se problemático pensar as peças como oriundas exclusivamente da genialidade individual do dramaturgo.

Desconstruindo velhas noções de imanência, intenção e originalidade, teóricos do pós-estruturalismo propuseram formas de abordar uma obra de arte que têm implicações na maneira como interpretamos Shakespeare. Em seu famoso ensaio "A morte do autor", Roland Barthes (2004, p. 62) afirma que "o escritor pode apenas imitar um gesto sempre anterior, jamais original; seu único poder está em mesclar as escrituras, em fazê-las contrariar-se umas pelas outras". Para Barthes (2004, p. 63), dar "ao texto um Autor é impor-lhe um travão, é provê-lo de um significado último, é fechar a escritura”. Esse deslocamento da figura do autor tem um significado particular quando se pensa no processo teatral colaborativo descrito acima. Seguindo a linha de Barthes, a teoria da intertextualidade proposta por Kristeva chamou a atenção para as intermináveis trocas textuais que fundamentam a produção de novos textos. Kristeva foi fortemente influenciada pelo pensamento de Bakhtin, cuja visão do romance como gênero multidiscursivo lança uma luz, também, no modo como podemos compreender a obra de Shakespeare, seja textualmente ou em/enquanto performance. Bakhtin (1981, p. 263) emprega o termo "heteroglossia" para se referir à coexistência de múltiplos discursos em meio às várias esferas de atividade linguística, os quais se manifestam por meio do discurso autoral, discurso dos narradores, gêneros inseridos e discurso das personagens. Ele acrescenta que o discurso é moldado por diversas forças com as quais se entrelaça, tais como pensamentos compartilhados, pontos de vista, julgamentos de valores e sotaques. Tendo adquirido forma e significado em um dado momento histórico, em um ambiente socialmente específico, o discurso se insere em uma teia de outros fios dialógicos, tornando-se um participante ativo no diálogo social. É importante sublinhar que a "heteroglossia" está atrelada a um conceito-chave dentro da teoria bakhtiniana: dialogismo. Para Bakhtin (1981, p. 276), o caráter inerentemente dialógico do discurso se revela no modo como um enunciado, quando direcionado a um objeto, entra numa relação dialógica com palavras estrangeiras, julgamentos de valor, sotaques; tudo isso molda o discurso e seu sentido. Além de se constituir a partir do já dito, o enunciado provoca uma resposta, antecipa-a e se estrutura na direção dela (BAKHTIN, 1981, p. 280). Bakhtin (1981, p. 263) 
ressalta que a interação dialógica entre os discursos e as linguagens que constituem a heteroglossia é um traço distintivo do romance ${ }^{4}$. Conforme veremos mais adiante, essas noções adquiriram especial relevância para os estudos de adaptação, cujas discussões têm ampliado significativamente o nosso entendimento dos diversos mecanismos adaptativos por meio dos quais Shakespeare é recriado em diferentes mídias.

Essa epistemologia pós-estruturalista nos estimula a repensar dicotomias como texto/performance, originalidade/cópia, fonte/texto, que ainda permeiam a leitura, produção e recepção de Shakespeare no século XXI. Como vimos, as peças foram inicialmente produzidas em/enquanto montagem, sem que se tivesse em vista uma projeção delas no mercado editorial da época. Emma Smith (2007, p. 49) nos lembra que foi graças a dois parceiros de Shakespeare, John Heminges e Henry Condell, que as peças foram reunidas numa coletânea e publicadas postumamente, em 1623. O First Folio, conforme foi chamada, reuniu 36 peças, 18 das quais não haviam sido previamente publicadas em edições individuais, os quartos. Os textos que haviam sido publicados nos quartos foram substancialmente alterados no First Folio, o que sinaliza o trabalho de edição e revisão extensivo empreendido por Heminges e Condell, com a finalidade de melhorar o texto (SMITH, 2007, p. 49). Esse trabalho de revisão é praticado até hoje e revela a natureza intertextual e interpretativa dos textos que chegam até nós, normalmente anunciados como originais e autenticamente shakespearianos. Na série The Oxford Shakespeare, por exemplo, os textos das peças vêm acompanhados de vários paratextos, como notas de rodapé explicativas e uma longa introdução, cuja finalidade é auxiliar na leitura e interpretação. Conforme aponta Smith (2007, p. 50), o texto editado de Shakespeare já foi interpretado para nós, e nossa interpretação é moldada por aquele ato anterior de interpretação editorial.

De caráter marcadamente intertextual, o trabalho editorial e interpretativo que fundamenta a reprodução textual das peças de Shakespeare torna incôngrua a retórica de fidelidade textual ainda invocada na produção e recepção de peças shakespearianas, especialmente no mundo anglófono. Além de possuir um valor literário amplamente reconhecido e reafirmado ao longo do tempo, a obra dramática de Shakespeare é difundida e moldada por meio de montagens teatrais e adaptações filmicas. Daniel Fischlin e Mark Fortier (2000, p. 1, tradução minha) afirmam que existem adaptações shakespearianas desde que as peças passaram a existir: por quase 400 anos, dramaturgos têm se apropriado delas e as recriado, de várias formas, para o palco. Produções teatrais e cinematográficas atuam como instrumentos importantes na ressignificação das obras shakespearianas a partir de um idioma contemporâneo que normalmente reflete os diversos contextos socioculturais em que são apresentadas.

Apesar de os dramas de Shakespeare terem sido inicialmente produzidos para performance, a canonização deles pela crítica literária estabeleceu uma hierarquia dicotômica entre texto versus palco/tela que posiciona o primeiro como veículo privilegiado para se ter acesso a significados "autenticamente shakespearianos". Estudos de performance tiveram um papel fundamental em buscar uma ruptura com essa hierarquia e elevar não apenas o palco, mas também todo o

4 Sue Vice (1997, p. 20) aponta que a heteroglossia está sempre articulada dialogicamente num texto, o que torna difícil falar sobre heteroglossia sem falar sobre dialogismo, e vice-versa. 
aparato teatral que rodeia uma montagem, posicionando-os como práticas importantes de significação. Essa nova ênfase em performance não deixou de lado, entretanto, o forte vínculo com o texto shakespeariano, típico de uma abordagem predominantemente literária, o que traz implicações para o modo como Shakespeare é interpretado no palco. William Worthen (1997, p. 4) aponta que olhar para o palco através de uma ótica literária situa a performance como um espaço de articulação de sentidos, gestos e temas inefavelmente localizados no texto, o qual é visto como fonte primária para a performance e como medida de seu sucesso. A montagem teatral é compreendida, assim, como canal de representação de uma dramaticidade inerente às peças e de preservação da autenticidade destas, sendo reduzida, desse modo, a uma transposição mecânica da linguagem, da estrutura, das personagens e dos significados supostamente imanentes ao texto. Essa visão essencialista universaliza a performance teatral, quando, por outro lado, seu caráter multidiscursivo ressalta a importância da interação dialógica de elementos textuais e não textuais nos processos de construção de sentido. Para James Bulman (1996, p. 1, tradução minha), olhar para os textos shakespearianos como entidades linguísticas estáveis e autorizadas não apenas posiciona atores e diretores como intérpretes, em vez de produtores de sentido, mas também negligencia a contingência radical da performance: "a interseção imprevisível, muitas vezes lúdica, de história, condições materiais, contextos sociais e recepção, que desestabiliza Shakespeare e torna a significação teatral um ato participativo". Em consonância com a noção bakhtiniana de dialogismo, Bulman aponta para um modo mais amplo de abordar a performance shakespeariana, o qual, sem deixar de levar em consideração o texto, não o localiza como fonte primária/originária de sentido. Desse modo,

[...] sentidos não são "traduzíveis" do texto, porque sentido no teatro surge da aplicação de práticas produtivas ao texto - comportamento, cenário, design, iluminação, movimento, todo o conjunto de práticas teatrais institucionalizadas que se situam fora e para além do texto (WORTHEN, 1997, p. 51-52, tradução minha).

Pensar o texto shakespeariano como um dos vários elementos discursivos que dialogicamente participam da construção do sentido de uma montagem teatral nos instiga a repensar os critérios de fidelidade textual e autenticidade que ainda influenciam o modo como espectadores e críticos respondem a performances teatrais shakespearianas. Partindo de uma concepção de "Shakespeare" como uma vasta rede constituída por adaptações anteriores, Douglas Lanier (2017, p. 297) ressalta que embora não se possa renegar completamente a ideia de fidelidade, ela deve ser pensada em relação não a um texto originário e centralizador, mas àquela teia de adaptações que continuamente reconfigura nosso entendimento da obra de Shakespeare.

A natureza heteroglota e dialógica da performance teatral shakespeariana também caracteriza o modo como Shakespeare ganha sentido em adaptações filmicas. Dennis Cutchins (2017, p. 75) chama a atenção para o impacto do conceito bakhtiniano de dialogismo nos estudos de adaptação. Para ele, o pensamento dialógico sugere que sentidos são negociados numa complexa rede de significados e diálogos intencionais e não intencionais. Além de desconstruir conceitos de influência, originalidade e fidelidade, conceber adaptações por um viés dialógico enfatiza a indeterminação que permeia os intermináveis diálogos 
por meio dos quais Shakespeare adquire sentido. Nessa mesma perspectiva, Robert Stam (2005, p. 27) sublinha que o dialogismo bakhtiniano nos ajuda a transcender as aporias da retórica de fidelidade e do modelo dicotômico fonte/ adaptação, o qual deixa de fora não apenas todos os textos suplementares que dialogicamente configuram uma adaptação, mas também a resposta dialógica de leitores/espectadores ${ }^{5}$. Essa concepção dialógica ecoa no modo como as negociações entre elementos textuais e extratextuais são abordadas nos estudos de adaptação shakespeariana. Julie Sanders (2006, p. 48, tradução minha) assinala que se

[...] o drama encarna, dentro de suas convenções genéricas, um chamado à reinterpretação, então o movimento para um modo genérico diferente pode estimular uma leitura do texto shakespeariano a partir de um novo e reformulado ponto de vista.

Especificidades genéricas do teatro e do cinema demandam que Shakespeare seja abordado de maneira distinta no palco e na tela, e isso, de fato, gera novas interpretações e ressignificações para os dramas em ambas as mídias. Maurice Hindle (2007, p. 12) observa que a maior diferença singular entre os métodos comunicativos do teatro e do cinema é que o primeiro é um meio essencialmente verbal, colocando em primeiro plano a palavra falada, enquanto o filme é comunicado predominantemente pelo uso de técnicas visuais ${ }^{6}$. Essa ênfase na imagem tem impacto no modo como o caráter intrinsecamente teatral e verbal das peças de Shakespeare é negociado em adaptações filmicas. Stam (2000, p. 61) ressalta a heterogeneidade do cinema, o qual abarca uma infinidade de outras linguagens e expressões artísticas (por exemplo, a música, a dança, a fotografia, a arquitetura, a performance e o teatro). Ao fornecer a adaptadores de Shakespeare uma variedade de recursos, a natureza heteroglota da linguagem cinematográfica expande consideravelmente as possibilidades de ressignificar as peças shakespearianas na tela. Chamando a atenção para os diferentes modos de adaptar Shakespeare, Sarah Hatchuel (2004, p. 16) enumera quatro tipos de adaptação, dois dos quais eu gostaria de destacar: aquelas que usam o texto "original" em inglês, mas o transformam por meio de cortes, alterações na ordem das cenas etc., como é o caso dos filmes de Henrique $V$ dirigidos por Laurence Olivier e Kenneth Branagh; e filmes inspirados nos enredos das peças de Shakespeare, mas que removem o texto completamente ou o inserem apenas em algumas cenas, a exemplo de West side story (1961) e Shakespeare apaixonado (1998). Adaptações de ambos os tipos são constituídas com base em vários elementos discursivos - por exemplo, o texto, o aparato cinematográfico, a intervenção editorial, a performance dos atores - por meio de cuja interação dialógica Shakespeare é reinventado. A despeito desse caráter heteroglota, adaptações filmicas shakespearianas, principalmente as da primeira categoria, ainda são julgadas pelo critério

5 Stam, nome de referência dentro dos estudos de adaptação, publicou obras que foram fortemente influenciadas pelo pensamento bakhtiniano, como Literature through film (2005) e Subversive pleasures: Bakhtin, cultural criticism, and film (1989). Sua abordagem dialógica de adaptação é mencionada em outra obra-chave desse campo de estudo: $A$ theory of adaptation, de Linda Hutcheon (2013, p. 21). Podem-se perceber marcas do dialogismo bakhtiniano no entendimento de Hutcheon (2013, p. 3) de que adaptações têm uma relação declarada e definidora com textos anteriores.

6 Hindle (2007, p. 3-11) aponta outras diferenças entre o teatro e o cinema. Como um filme é um meio de performance gravada, um produto completo mostrado no cinema ou em vídeo/DVD, em um espaço inteiramente remoto daquele em que foi inicialmente produzido, espectadores não exercem um efeito na performance. Já no teatro, onde a encenação é ao vivo, há sempre alguma interação entre o palco e a plateia. Além disso, o teatro possibilita que o público escolha elementos da performance em que querem se concentrar, enquanto no cinema é a câmera que direciona o foco por meio das escolhas feitas pelo(a) diretor(a). 
de fidelidade textual, o que vai de encontro, também, à ampla contestação dessa ideia dentro dos estudos de adaptação ${ }^{7}$. Michael Anderegg (2004, p. 12, tradução minha) destaca que os filmes shakespearianos mais empolgantes são "os que encontram meios de traduzir as energias da linguagem de Shakespeare para uma linguagem audiovisual própria”. Tais considerações revelam um olhar textocêntrico que situa o sentido das peças de Shakespeare num ponto fixo, o texto, cujas "energias" devem ser traduzidas para a tela. Na atual era de pós-fidelidade (LANIER, 2014), torna-se mais pertinente perceber o significado de adaptações shakespearianas não como materialização de sentidos originários num texto centralizador, mas a partir da heteroglossia da qual elas dialogicamente se constituem.

Nas produções de Rei Lear que discutirei abaixo, veremos como a conotação beckettiana que elas adquiriram entre espectadores e críticos reitera o caráter heteroglota da montagem/adaptação shakespeariana, e reafirma o valor das negociações dialógicas entre o texto e elementos não textuais na ressignificação dessa tragédia no palco e na tela. O viés bakhtiniano adotado aqui lança um novo olhar sobre a influência de Beckett nos Lears de Brook, comumente apontada em estudos sobre recriações anglófonas de Rei Lear ${ }^{8}$.

\section{REI LEAR, NOSSO CONTEMPORÂNEO}

A montagem do diretor britânico Peter Brook, em 1962, para a Royal Shakespeare Company (RSC), é um marco na história teatral de Rei Lear e até hoje influencia a maneira como a peça é lida, performada e adaptada, especialmente no mundo anglófono. Jonathan Bate e Eric Rasmussen (2009, p. 166) assinalam que as produções de Lear nunca mais foram as mesmas depois da de Brook; desde então, poucas montagens não seguiram, em algum aspecto, a linha dele. Conforme veremos a seguir, Brook empregou uma estética minimalista e um estilo performático desprovido de emoção que evocaram elementos dramáticos característicos do teatro de Samuel Beckett, estabelecendo, desse modo, um elo entre Lear e o Teatro do Absurdo que foi fundamental na reinvenção da peça entre os anos 1960 e 1970. Para entender melhor como a montagem ganhou essa significação beckettiana, primeiro no palco e posteriormente na tela, farei um breve levantamento sobre o impacto de Beckett na cena teatral britânica da época, observando especialmente como sua estética revolucionária influenciou o desenvolvimento de métodos de encenar Shakespeare na RSC.

Waiting for Godot (Esperando Godot) rompeu drasticamente com velhas convenções que ainda dominavam o teatro britânico e europeu em meados da década de 1950, tais como noções aristotélicas de desenvolvimento de enredo e o uso de cenários naturalistas. Em vez de contar uma história com começo, meio e fim, Godot se centra na espera de Vladimir e Estragon por Godot, o qual nunca chega. Os dois encenam uma série de atos lúdicos e reflexões metafísicas, que funcionam como estratégias para passar o tempo enquanto aguardam pelo demorado

\footnotetext{
7 Em Literature through film, Stam (2005, p. 3-4) questiona a possibilidade de se atingir fidelidade absoluta. Para ele, adaptação é automaticamente diferente e original devido à mudança de mídia. A transição de um meio de via unicamente verbal, como o romance, para um multimodal, como o cinema, o qual se utiliza de palavras, música, efeitos sonoros e imagens em moção, explica a improbabilidade da fidelidade literal. Para saber mais sobre a crítica de fidelidade, ver, também: Hutcheon (2013, p. 6-7), Johnson (2017, p. 87-101) e Baker (2009, p. 2-4).

8 Ver, por exemplo: Halio (2001, p. 102-103), Barnet (1998, p. 256), Leggatt (2004, p. 46) e Foakes (2002, p. 153-154).
} 
encontro com o misterioso sr. Godot. A peça se passa numa estrada vazia, próxima a uma árvore murcha; um cenário vago que não faz remissão a espaços geográficos ou contextos históricos específicos ${ }^{9}$. A resistência de Beckett em fornecer respostas claras para perguntas acerca da identidade de Godot ou da motivação dramática para a espera interminável de Vladimir e Estragon gerou comoção entre espectadores e críticos teatrais que assistiram à première da peça em Londres, em 1955. O diretor Peter Hall (2000, p. 115) lembra que, na primeira noite, houve bocejos e roncos de deboche, respostas hostis e expressões de tédio. O caráter marcadamente não convencional de Godot claramente não correspondeu às expectativas da plateia acerca do que deveria caracterizar uma obra dramática em/enquanto performance. Sem conseguir entender a peça, espectadores e críticos equivocadamente a julgaram por meio de comparações com obras teatrais mais tradicionais, cujas convenções Godot estava subvertendo. Depois que o influente crítico Kenneth Tynan ${ }^{10}$ proclamou que a peça era uma obra-prima do teatro moderno, ela logo ganhou um amplo apelo entre leitores e espectadores da época. Godot alterou drasticamente a percepção deles sobre a atividade teatral, além de ampliar o escopo interpretativo sobre o que o teatro poderia significar. As obras beckettianas encenadas e publicadas depois de Godot trouxeram novos experimentos verbais e formas artísticas altamente subversivas, que testaram os limites da estética minimalista do dramaturgo. Embora sua obra dramática não seja vista como parte do alto modernismo europeu dos anos 1920, ela ecoou o credo dos escritores modernistas - "Faça-o novo" - com cada nova obra sendo apresentada como uma inovação tanto de antigas convenções quanto de obras prévias do próprio Beckett (KENNEDY, 1989, p. 47).

Esperando Godot - a peça mais famosa de Beckett - não apenas se tornou um clássico teatral; ela já foi absorvida no teatro de nossa época (GRAVER, 2004, p. 86) e acumulou um imenso capital cultural ao longo do tempo. Apresentada como uma tragicomédia em dois atos, seu modo de apresentação propulsionou uma redefinição do significado e da natureza da tragicomédia. O imagético minimalista da peça é um emblema do teatro moderno: um palco vazio, uma árvore e duas personagens aparentemente itinerantes esperando Godot. Sem fazer referência a nenhuma localização geográfica reconhecivel, esse cenário icônico é apontado como um espaço arquétipo que pode representar qualquer lugar ou qualquer época, conforme McDonald (2006, p. 50) afirma. De modo geral, as peças de Beckett são repletas de componentes visuais e performáticos que lhes conferem uma significação ao mesmo tempo localizada e universal. Isso explica, em parte, o duradouro impacto cultural delas dentro - e para além - do movimento conhecido como Teatro do Absurdo.

A emergência de Beckett como recurso dramático para produzir Shakespeare ocorreu em paralelo ao destaque que ele alcançou enquanto líder do Teatro do Absurdo e à fundação da Royal Shakespeare Company. Desde que surgiu, em 1961, a RSC tem sua sede principal e seus teatros próprios (o Royal Shakespeare Theatre e o Swan Theatre) em Stratford-upon-Avon, cidade onde Shakespeare nasceu, com um repertório que sempre incluiu, também, obras não shakespearia-

9 Não é objetivo deste artigo discutir Godot detalhadamente. Para estudos dedicados à peça, ver: McDonald (2006, p. 29-43) e Graver (2004).

10 Tynan (1955, tradução minha) declarou que Godot o forçou a "reexaminar as regras que tinham até então orientado o drama, e ao fazê-lo, revelou-as não elásticas o suficiente". 
nas. Situada em Stratford e encenando Shakespeare a partir dos textos que conhecemos como "originais", a RSC criou para si um etos de epicentro global de performance shakespeariana, onde discutivelmente se produz um Shakespeare verdadeiramente autêntico. Enquanto diretor artístico da recém-fundada RSC, Peter Hall teve um papel fundamental no desenvolvimento de um estilo dramático único para a companhia, o qual se constituiu, principalmente, de dois aspectos: ênfase na representação precisa do verso shakespeariano ${ }^{11}$ e busca por ressaltar a atualidade das peças. Tendo dirigido Godot, Hall estava a par do imenso impacto da peça na cena teatral britânica do período. Para ele, estabelecer conexões entre Shakespeare e peças contemporâneas era a chave para modernizar as obras do dramaturgo, sem minar a autoridade do texto shakespeariano. Numa fala feita no início dos anos 1960, Hall destacou que a obra de Beckett e de outros dramaturgos contemporâneos iluminavam ou refletiam aspectos daquele período. Nesse sentido, estabelecer paralelos entre Shakespeare e esses dramaturgos potencialmente levaria espectadores a explorarem a contemporaneidade das peças shakespearianas. Referindo-se a Rei Lear, ele declarou: "há coisas em Lear que falam para o agora, que são parte da sensibilidade beckettiana de agora"12. O discurso de Hall traz à tona algumas ambivalências da abordagem da RSC em relação a Shakespeare. O uso de teatro moderno para atualizar a obra shakespeariana revela a natureza heteroglota das montagens da RSC e indica como a interação dialógica entre o texto de Shakespeare e outros recursos dramáticos nos quais a performance era fundamentada minimizava a força centralizadora de Shakespeare como principal fonte de significado. Por outro lado, esse aspecto multidiscursivo da performance shakespeariana é apresentado como traço imanente do texto de Shakespeare, como se uma leitura beckettiana de Rei Lear já estivesse latente no texto, apenas esperando para ser liberada. Collin Chambers (2004, p. 118, tradução minha) assinala que o diretor "queria honrar as verdades daqueles textos, conforme percebidas quatro séculos depois, sem fingir que elas eram facilmente acessiveis ou uniformemente cativantes". Ele tinha de negociar seu impulso de apresentar Shakespeare por meio de uma linguagem contemporânea - utilizando-se de mecanismos intertextuais que, consequentemente, minavam a autoridade do texto shakespeariano - e o status canônico do dramaturgo a cujo nome o sucesso da companhia estava atrelado. As expectativas do público também estavam em jogo. Margaret Kidnie (2009, p. 24) nos lembra que entre falantes do inglês há uma insistência preponderante de que a verdadeira essência das obras de Shakespeare está na linguagem. Enquanto essa visão textocêntrica da performance shakespeariana pretere outros elementos além do texto que, conforme vimos, são cruciais para tornar Shakespeare atual no palco, ela reitera a heteroglossia na qual o discurso da plateia interage dialogicamente com outras linguagens e discursos na construção de sentidos.

Essa interação dialógica entre texto e performance permeou o modo como o Rei Lear de Brook adquiriu uma significação beckettiana ${ }^{13}$. A montagem rompeu

11 Conforme aponta Sally Beauman (1982, p. 268), Hall queria desenvolver uma nova abordagem do verso que suplantasse estilos retóricos e naturalistas que dominavam montagens shakespearianas na Inglaterra antes da fundação da RSC.

12 Tradução minha de uma entrevista que transcrevi a partir de um áudio encontrado no Sound Archive da British Library (número de referência: 1CDR0015784 BD1-BD7 NSA). A data exata da entrevista não foi especificada.

13 Como não há registros em vídeo dessa montagem, minha análise se baseou em fotos, outros materiais coletados no Shakespeare Birthplace Trust e no relato fornecido por Leggatt (2004), o qual teve a oportunidade de assistir ao espetáculo. 
com abordagens romantizadas e naturalistas que até então tinham sido continuamente empregadas para performar a peça na Inglaterra. O modo pelo qual Brook (2008, p. 105, tradução minha) interpretava Lear, como um "poema coerente esboçado para estudar o poder e o vazio do nada", originou uma montagem sombria, desprovida de qualquer sinal de consolação e alivio das emoções. O tom lúgubre e a estética minimalista foram atribuídos, principalmente, à resposta de Brook ao crítico Jan Kott ${ }^{14}$ e a Beckett. O assistente de palco de Brook, Charles Marowitz (1963, p. 104), lembra que, durante os ensaios, a referência deles era sempre beckettiana. Referindo-se aos traços grosseiros do cenário e dos figurinos, ele observou que "o mundo desse Lear, assim como o mundo de Beckett, está em constante estado de decomposição” (MAROWITZ, 1963, p. 104, tradução minha). Esse senso de deterioração - fortemente dramatizado na peça beckettiana Endgame (Fim de partida) - foi representado, principalmente, no aspecto visual. Os cenários eram quase vazios, com apenas alguns elementos cênicos feitos de madeira bruta e metais enferrujados. Na cena em que Lear dividiu seu reinado, por exemplo, havia um ciclorama branco no fundo, dois grandes painéis também brancos nos quais estavam penduradas folhas de metal enferrujadas e, mais à frente, um banco de madeira e uma mesa com alguns utensílios visivelmente desgastados (KENNEDY, 1993, p. 172). Foi durante as cenas de Dover que as marcas do teatro de Beckett se tornaram mais perceptíveis. Acompanhado do filho Edgar - disfarçado como o pobre Tom -, o cego Gloucester é convencido de que está caminhando em direção a um precipício de onde ele pretende pular, quando, na verdade, está apenas numa plataforma lisa. Ao se jogar, a personagem obviamente cai no palco vazio, até ser novamente ludibriado pelo disfarçado Edgar, que faz o pai acreditar que sobreviveu milagrosamente a uma queda mortal. Em sua análise comparativa entre Rei Lear e a dramaturgia de Beckett, Kott (1967, p. 118, tradução minha) nota que a tentativa de suicídio de Gloucester retoma a peça beckettiana Act without words: "é meramente uma cambalhota circense em um palco vazio". Invocando a leitura de Kott, Brook situou a cena numa plataforma cujo vazio evocou o terreno descampado emblemático de Esperando Godot. Igualmente beckettiano foi o encontro de Lear e Gloucester, um dos momentos mais dilacerantes da peça. No texto, o enlouquecido Lear cinicamente fala sobre mortalidade, ingratidão, denuncia a injustiça do poder e esbraveja seu ódio contra a sexualidade feminina. Sem avançar o enredo, a cena atrasa a continuação da ação que leva à morte de Lear, suas filhas e Edmund, no final. A insistência de Lear de que ele ainda é rei torna a cena ainda mais penosa e sublinha o potencial dela para expressar sofrimento. Nas mãos de Brook, entretanto, as falas das personagens foram pronunciadas num tom desprovido de emoção que não conseguiu exprimir o pathos trágico sugerido no texto. A apropriação de uma sensibilidade beckettiana foi essencial num movimento de ruptura com interpretações naturalistas focadas em emocionar espectadores e levá-los a ter empatia por Rei Lear.

Enquanto alguns críticos acharam que a abordagem sombria de Brook fez com que Rei Lear perdesse sua essência, a maioria deles recebeu a montagem com grande entusiasmo. Kenneth Tynan (1962, tradução minha) afirmou que "quando o conceito [beckettiano] se encaixa, algo que se percebe na maior

14 Kott (1967, p. 100-133) havia publicado, na época, um ensaio intitulado "King Lear, or Endgame", no qual traça um paralelo entre Rei Lear e obras de Beckett como Endgame, Waiting for Godot e Act without words. 
parte da performance, ele se incendeia na sua cabeça”. Apesar da conotação beckettiana que a montagem ganhou, não houve alterações textuais radicais que, se pensarmos nas drásticas diferenças entre a dramaturgia de Shakespeare e de Beckett, deveriam ser contempladas em qualquer tentativa de performar Shakespeare sob um prisma beckettiano. Esse cuidado com o texto foi reflexo do estilo de performance predominantemente textocêntrico adotado pela RSC na época, o qual, conforme vimos, fundamentava-se numa negociação dialógica entre o reverenciado verso de Shakespeare e a intenção de modernizar as peças do dramaturgo a partir da assimilação de influências do teatro moderno. Mas mesmo sem um tratamento mais experimental do texto shakespeariano, o cruzamento dialógico do texto com elementos visuais e performáticos reconhecidamente beckettianos permitiu que Rei Lear fosse significativamente reinventada sob uma ótica contemporânea.

Anos mais tarde, Brook referiu-se ao caráter beckettiano de sua montagem como uma simplificação jornalística, já que Beckett foi, para ele, simplesmente evocado como estratégia para concretizar certas imagens durante os ensaios, em vez de ser empregado como um conceito central para a montagem (LABEILLE; BROOK, 1980, p. 220). De fato, atribuir a Beckett a significação da performance como um todo é deixar de considerar outros elementos que constituíram o sentido desse Lear, como a apropriação de formas dramáticas associadas com os dramas de Brecht e Artaud ${ }^{15}$. Embora Beckett não tenha sido a única fonte não shakespeariana para o Lear de Brook, a afinidade com o teatro beckettiano ganhou destaque entre espectadores já familiarizados com o teatro de Beckett e os métodos de encenação empregados pela RSC na época. J. Trewin (1971, p. 129) nos informa que, depois da première, a plateia paulatinamente reconheceu que Brook havia dirigido um Lear beckettiano, uma espécie de Endgame shakespeariano. Essa resposta chama a atenção para a importância dos espectadores e do contexto no modo como as peças de Shakespeare são constantemente ressignificadas por meio da performance. A conotação beckettiana da montagem reforça os mecanismos multidiscursivos por meio dos quais Shakespeare ganha sentido dialogicamente para além do texto e reconfigura nosso entendimento da peça não como um objeto estável, mas como um processo dinâmico que se molda em resposta aos diferentes contextos de produção e recepção.

A interpretação de Brook (2008, p. 105, tradução minha) de que Rei Lear é um "poema coerente elaborado para estudar a força e o vazio do nada" foi explorada ainda mais a fundo em sua adaptação filmica da peça, inicialmente lançada em 1970. Se usarmos a classificação de Hatchuel (2004), perceberemos que se trata de um filme em que o texto shakespeariano é usado, mas cortado e reorganizado de acordo com a interpretação do diretor. Hatchuel (2004, p. 23) também categoriza o Lear de Brook como um filme de vanguarda que rompeu com técnicas de filmagem e edição realistas empregadas em filmes anteriores como o Hamlet de Olivier (1948) e o Romeu e Julieta de Franco Zeffirelli (1968). De fato, Brook adotou uma estética fragmentada e antirrealista que se contrapõe a um modelo hollywoodiano amplamente explorado em filmes shakespearianos mais convencionais, como os de Zeffirelli e Branagh ${ }^{16}$. Russell Jackson (2007, p. 15)

\footnotetext{
15 Em sua obra The shifting point, Brook (1988, p. 54, tradução minha) ressalta que "tudo que há de notável em Brecht, Beckett e Artaud está em Shakespeare".

16 Stam (2005, p. 11, tradução minha) destaca que Hollywood “inventou um jeito de contar histórias através de uma organização
} 
afirma que, em termos filmicos, as adaptações mais conservadoras de peças de Shakespeare são aquelas que adotam o maior número possivel de elementos linguísticos e estruturais das peças e os adaptam de acordo com regras do cinema convencional: edição contínua, clareza na caracterização e na história, e inteligibilidade na fala. Contrário a esse viés, Brook elaborou uma linguagem metadramática que, constituída a partir de uma intricada fusão de recursos textuais, teatrais e cinematográficos, expõe as marcas de enunciação do filme, quebrando, desse modo, a ilusão de realidade. Conforme veremos, os traços alienantes do filme são elementos-chave na reinvenção de Rei Lear para além de abordagens mais convencionais que romantizam a peça e frisam seu potencial de comover espectadores.

O tom sombrio do filme é estabelecido desde a primeira cena, na qual Lear divide o reino, deserda Cordélia e bane Kent. A cena acontece em uma sala fechada, minimamente decorada com dois bancos, de onde as personagens assistem ao rito de repartição da coroa, e, ao centro, o trono de Lear. Ele inicia seu discurso com "Know" ("Saibam"), que, seguido de uma pausa, confunde-se com o homônimo "no" ("não") em inglês, evocando um sentido de negação que anuncia o pessimismo marcante que perpassa todo o filme. Enquadrado em close-up, Lear parece abatido, fatigado, já entre a vida e a morte, imagem reforçada pelo enorme trono com aparência de caixão e pela lentidão com que ele fala, pausando a cada palavra e adotando um tom baixo que beira o sussurro. Essa imagem lúgubre evoca, desde o início, um senso de deterioração que vai sendo reiterado no decorrer do filme. A cena rompe com abordagens tradicionais que optam por uma representação bem delineada da trajetória que Lear percorre do reinado ao seu completo declínio. Igualmente subversivas são as pausas entrepostas entre os trechos da fala da personagem. Embora elas permeiem todas as cenas em que Lear aparece, tornam-se mais conspícuas nas cenas iniciais e finais do filme. As pausas não apenas atrasam o avanço da narrativa, mas também funcionam como mecanismo metadramático que, ao chamar a atenção para a artificialidade da performance filmada, cria um efeito de distanciamento. Essas interrupções sinalizam a presença de uma estética marcadamente beckettiana no filme de Brook. É válido notar que a pausa é um emblema do estilo dramático de Beckett e aparece com frequência em peças como Godot, Endgame e Happy days. No palco, as pausas não apenas interrompem o desenvolvimento ação dramática, mas também ressaltam o caráter repetitivo e estagnado das peças que, por sua vez, funciona como recurso metadramático. Ao se apropriar dessa estética de ruptura marcadamente teatral, Brook tanto rompe com abordagens realistas convencionalmente empregadas em filmes shakespearianos como também revela a complexa interação dialógica entre as linguagens teatral e filmica por meio da qual seu Lear adquire sentido.

Os recursos de edição do cinema deram a Brook a oportunidade de estreitar ainda mais a afinidade entre o filme e o idioma fragmentado das peças de Beckett. Em vez de usar técnicas de edição típicas de filmes realistas que criam uma narrativa impecavelmente ininterrupta, o diretor optou por mecanismos que evidenciam a descontinuidade entre as cenas e expõem as marcas de enunciação do filme. O momento em que Kent se transforma em Caius, por exemplo, é inter-

cinemática de tempo e espaço". Esse modelo hollywoodiano tornou-se um marco estético do cinema dominante, o qual enfatiza "a reconstituição de um mundo ficcional caracterizado pela coerência interna e pela aparência de continuidade". 
polado por técnicas de fade in, fade out e jump cuts, as quais ressaltam o modo como a sequência se constitui a partir de um processo de montagem de várias tomadas. A ausência de música não diegética é outro traço marcante da linguagem metacinemática desse Lear. Deborah Cartmell e Imelda Whelehan (2007, p. 10, tradução minha) apontam que "a música contribui para o tom, amplifica emoções, enfatiza temporalidade, cultura ou era, e pode gerar continuidade entre cortes e edições". Além de deixar exposto o aspecto descontínuo do filme, a inexistência de música extradiegética dificulta a imersão dos espectadores no universo diegético de Lear, já que não são induzidos a responderem emocionalmente aos diferentes momentos da narrativa filmica. Essa supressão de recursos musicais extradiegéticos acentua o vínculo do filme com convenções teatrais tipicamente beckettianas. É válido lembrar que, em Beckett, a sensação de estagnação transmitida pelas repetidas pausas e silêncios é amplificada pela ausência de música não incidental, a qual, no teatro, contribui para a criação de ilusão cênica e de uma continuidade coerente entre as cenas. No filme, a combinação desse elemento sonoro com o emprego de um estilo de atuação desprovido de emoção e de cenários espacialmente limitados cria uma narrativa anticlimática cuja invariabilidade evoca a estrutura repetitiva das peças de Beckett. Esse vínculo é reforçado na cena final. Filmada em close-up e em silêncio absoluto, a cena mostra Lear sucumbindo para fora do foco da câmera, deixando à mostra apenas uma tela branca que reitera o efeito estático e as conotações pessimistas da primeira cena. A impressão que se tem é de que o filme termina como começa, o que remete à circularidade da estrutura dramática das peças de Beckett.

Embora o Rei Lear filmico de Brook seja o registro mais próximo de sua legendária montagem de 1962, a adaptação não pode ser compreendida como uma simples tradução da performance teatral para a tela. O filme se construiu a partir da negociação entre textos, linguagens e discursos cujo cruzamento dialógico reconfigurou o sentido de Rei Lear, que adquiriu uma nova significação entre espectadores do início da década de 1970, mesmo para aqueles que antagonizaram a abordagem de Brook. Críticos como Norman Berlin e Pauline Kael reprovaram a adaptação veementemente, considerando inaceitável o sentido beckettiano que a peça ganhou no filme, o que ambos entenderam como um ato de infidelidade textual inaceitável ${ }^{17}$. A resposta hostil desses críticos americanos se distingue do entusiasmo com que espectadores da RSC, já familiarizados com Beckett e os métodos de encenar Shakespeare empregados pela companhia, reagiram ao Lear teatral de Brook. Essas respostas divergentes reforçam o papel-chave não apenas dos espectadores na construção de sentido das peças, mas também do contexto em que Shakespeare é reinventado e recebido. As duas produções aqui discutidas reiteram a natureza heteroglota da performance e da adaptação shakespearianas, e reafirmam o valor da interação dialógica entre elementos textuais e não textuais no modo como Rei Lear é continuamente reinventada, seja por meio da leitura, de montagens teatrais ou adaptações cinematográficas.

\footnotetext{
7 Berlin (1977, p. 299) destacou que Rei Lear deveria ser tratada de modo fiel e, portanto, o filme de Brook merecia ser desprezado por ridicularizar o original, tratando-o como se fosse uma peça de Beckett. Na mesma perspectiva, Kael (2000, p. 356), que declarou ter odiado o filme, questionou: se Endgame veio de Lear, conforme Kott sugere, qual o propósito de se basear Lear
} em Beckett? 


\section{KING LEAR: TEXT, PERFORMANCE, AND ADAPTATION}

Abstract: This article examines how King Lear acquires meaning on stage and screen through adaptive practices that go beyond the Shakespeare text. Bakhtin's (1981) notions of heteroglossia and dialogism provide us with a useful framework to understand the dialogic interplay of various texts, languages, and discourses through which King Lear is reinvented in different contexts and media. Looking at the play from a dialogic angle widens the scope of a text-centred view of Shakespeare that positions the text both as a stable artefact and the primary source of meaning in productions and adaptations of Shakespeare's works. We shall see how Lear was reimagined distinctively through associations with modern theatre in a stage production and a film adaptation of the play.

Keywords: Shakespeare. King Lear. Performance. Adaptation. Bakhtin.

\section{REFERÊNCIAS}

ANDEREGG, M. A. Cinematic Shakespeare. Lanham: Rowman \& Littlefield, 2004. BAKER, B. Introduction. In: BAKER, B. (org.). Textual revisions: reading literature and film. Chester: Chester Academic Press, 2009. p. 1-29.

BAKHTIN, M. Discourse in the novel. In: BAKHTIN, M. Dialogic imagination: four essays. Austin: University of Texas Press, 1981. p. 259-422.

BARNET, S. King Lear on stage and screen. In: SHAKESPEARE, W. The tragedy of King Lear. 2. ed. New York: New American Library, 1998. p. 249-260.

BARTHES, R. A morte do autor. In: BARTHES, R. O rumor da língua. Tradução Mario Laranjeira. São Paulo: Martins Fontes, 2004. p. 57-64.

BATE, J.; RASMUSSEN, E. R. King Lear in performance: the RSC and beyond. In: BATE, J.; RASMUSSEN, J. (org.). King Lear. Basingstoke: Macmillan, 2009. p. 155-202.

BEAUMAN, S. The Royal Shakespeare Company: a history of ten decades. Oxford: Oxford University Press, 1982.

BERLIN, N. Peter Brook's interpretation of King Lear: nothing will come of nothing. Literature/Film Quarterly, v. 5, n. 4, p. 299-303, 1977.

BLOOM, H. The western canon. London: Harcourt Brace, 1994.

BLOOM, H. Shakespeare: the invention of the human. New York: Riverhead Books, 1998.

BRADLEY, A. C. Shakespearean tragedy. London: MacMillan, 1966.

BROOK, P. The empty space. London: Penguin, 2008.

BROOK, P. The shifting point. London: Methuen Drama, 1988.

BULMAN, J. C. Introduction: Shakespeare and performance theory. In: BULMAN, J. C. (org.). Shakespeare, theory, and performance. London: Routledge, 1996. p. 1-11.

CARTMELL, D.; WHELEHAN, I. Introduction. In: CARTMELL, D.; WHELEHAN, I. (org.). The Cambridge companion to literature on screen. Cambridge: Cambridge University Press, 2007. p. 1-12. 
CHAMBERS, C. Inside the Royal Shakespeare Company: creativity and the institution. London: Routledge, 2004.

CUTCHINS, D. Bakhtin, intertextuality, and adaptation. In: LEITCH, T. (org.). The Oxford handbook of adaptation studies. Oxford: Oxford University Press, 2017. p. 71-86.

FISCHLIN, D.; FORTIER, M. General introduction. In: FISCHLIN, D.; FORTIER, M. (org.). Adaptations of Shakespeare: a critical anthology of plays from the seventeenth century to the present. London: Routledge, 2000. p. 1-22.

FOAKES, R. A. King Lear and Endgame. Shakespeare survey. Cambridge: Cambridge University Press, 2002. p. 153-158.

FOAKES, R. A. Introduction. In: SHAKESPEARE, W. King Lear. London: Thomson Learning, 2001. p. 1-151.

GRAVER, L. Samuel Beckett, Waiting for Godot. Cambridge: Cambridge University Press, 2004.

GUNTNER, J. L. Hamlet, Macbeth and King Lear on film. In: JACKSON, R. (org.). The Cambridge companion to Shakespeare on film. 2. ed. Cambridge: Cambridge University Press, 2007. p. 120-140.

HALIO, J. Introduction. In: SHAKESPEARE, W. The tragedy of King Lear. Cambridge: Cambridge University Press, 2005. p. 1-94.

HALIO, J. L. King Lear: a guide to the play. Westport: Greenwood Press, 2001.

HALL, P. Making an exhibition of myself. London: Oberon, 2000.

HATCHUEL, S. Shakespeare: from stage to screen. Cambridge: Cambridge University Press, 2004.

HINDLE, M. Studying Shakespeare on film. Basingstoke: Palgrave Macmillan, 2007.

HOLDERNESS, G. Cultural Shakespeare. Hatfield: University of Hertfordshire, 2001.

HUTCHEON, L. A theory of adaptation. New York: Routledge, 2013.

JACKSON, R. From play-script to screenplay. In: JACKSON, R. (org.). The Cambridge companion to Shakespeare on film. 2. ed. Cambridge: Cambridge University Press, 2007. p. 15-34.

JOHNSON, B. To the memory of my beloved, the author Mr. William Shakespeare. In: FERGUSON, M. et al. (org.). The Northon anthology of poetry. 5. ed. London: W. W. Northon \& Company, 2005. p. 342-344.

JOHNSON, D. T. Adaptation and fidelity. In: LEITCH, T. (org.). The Oxford handbook of adaptation studies. New York: Oxford University Press, 2017. p. 88-101. JOWETT, J. Introduction. In: SHAKESPEARE, W.; MIDDLETON, T. The life of Timon of Athens. Oxford: Oxford University Press, 2008. p. 1-153.

KAEL, P. Peter Brook's "Night of the Living Dead". In: KAEL, P. Deeper into movies: the essential Kael Collection: from '69 to '72. London: Marion Boyars, 2000. p. 354-357.

KENNEDY, A. K. Samuel Beckett. Cambridge: Cambridge University Press, 1989. KENNEDY, D. Looking at Shakespeare. Cambridge: Cambridge University Press, 1993. 
KIDNIE, M. J. Shakespeare and the problem of adaptation. London: Routledge, 2009.

KOTT, J. Shakespeare our contemporary. London: Methuen, 1967.

LABEILLE, D.; BROOK, P. The formless hunch: an interview with Peter Brook. Modern Drama, v. 23, n. 3, p. 221-226, Fall 1980.

LANIER, D. Shakespeare/Not Shakespeare: afterword. In: DESMET, C.; LOPER, N.; CASEY, J. (org.). Shakespeare/Not Shakespeare. Cham: Palgrave Macmillan, 2017. p. 293-306.

LANIER, D. Shakespearean rhizomatics: adaptation, ethics, value. In: HUANG, A.; RIVLIN, E. (org.). Shakespeare and the ethics of appropriation. New York: Palgrave MacMillan, 2014. p. 21-40.

LEGGATT, A. King Lear. Manchester: Manchester University Press, 2004.

MAROWITZ, C. Lear Log. The Tulane Drama Review, v. 8, n. 2, p. 103-121, 1963.

McDONALD, R. The Cambridge introduction to Samuel Beckett. Cambridge: Cambridge University Press, 2006.

SANDERS, J. Adaptation and appropriation. London: Routledge, 2006.

SHAKESPEARE, W. Rei Lear. Tradução Millôr Fernandes. Porto Alegre: L\&PM, 1997.

SMITH, E. The Cambridge introduction to Shakespeare. Cambridge: Cambridge University Press, 2007.

STAM, R. Literature through film. Oxford: Blackwell, 2005.

STAM, R. Subversive pleasures: Bakhtin, cultural criticism, and film. Baltimore: Johns Hopkins University Press, 1989.

STAM, R. Beyond fidelity. In: NAREMORE, J. (org.). Film adaptation. London: Athlone, 2000. p. 54-76.

TREWIN, J. C. Peter Brook: a biography. London: MacDonald, 1971.

TYNAN, K. A world without gods or hope. The Observer, 1962.

TYNAN, K. New writing. The Observer, 1955.

VICE, S. Introducing Bakhtin. Manchester: Manchester University Press, 1997.

WELLS, S. Shakespeare: the poet and his plays. London: Methuen, 2001.

WORTHEN, W. B. Shakespeare and the authority of performance. Cambridge: Cambridge University Press, 1997. 